Izumi, Volume 8 No 2, 2019

e-ISSN: 2502-3535 p-ISSN: 2338-249X

Tersedia online di http://ejournal.undip.ac.id/index.php/izumi

\title{
Budaya Permintaan Maaf Di Tempat Kerja Dalam Drama Jepang: Tinjauan Sosiolinguistik
}

\author{
Eka Marthanty Indah Lestari \\ Universitas Brawijaya \\ lestari.eka86@ub.ac.id
}

\begin{abstract}
Abstrak
Permintaan maaf merupakan tindakan di mana seseorang menyatakan penyesalan atas kesalahan yang telah dilakukan. Tata cara dalam meminta maaf berkaitan erat dengan budaya yang berlaku di suatu tempat. Secara umum, penelitian ini bertujuan untuk mendapatkan gambaran mengenai budaya permintaan maaf di tempat kerja di Jepang. Selanjutnya, secara khusus tujuan penelitian ini adalah: 1) mengidentifikasi ungkapan permintaan maaf yang digunakan di tempat kerja; 2) mengidentifikasi strategi permintaan maaf yang digunakan di tempat kerja; dan 3) menganalisis aspek-aspek yang mempengaruhi pemilihan ungkapan dan strategi permintaan maaf. Metode penelitian yang digunakan adalah kualitatif, sedangkan permasalahan penelitian ditinjau dari perspektif sosiolinguistik. Sumber data dalam penelitian ini adalah drama Jepang berjudul Haken no Hinkaku (2007). Dalam drama tersebut ditemukan 78 (tujuh puluh delapan) ungkapan permintaan maaf yang digunakan di tempat kerja. Strategi permintaan maaf yang digunakan di antaranya: 1) meminta maaf secara langsung; 2) memberikan penjelasan atau mengemukakan alasan; 3) bertanggungjawab; 4) menawarkan penggantian barang; dan 5) berjanji untuk tidak mengulangi kesalahan yang sama. Selanjutnya, aspek-aspek yang berperan dalam pemilihan ungkapan dan strategi permintaan maaf, yaitu situasi, bobot kesalahan yang diperbuat, dan status lawan bicara.
\end{abstract}

Kata kunci: permintaan maaf; ungkapan permintaan maaf; strategi permintaan maaf; sosiolinguistik.

\begin{abstract}
(Title: The Apology Culture in Workplace in The Japanese Drama: A Sociolinguistic Overview). The apology is an action in which a person states his/her regret on the mistake which he/she did. The procedures in apology are closely related to the culture which is applicable in a region. This research in general aims to understand the apology culture in the workplace of Japan. The specific objectives of this research are 1) to identify the expression of apology used in the workplace; 2) to identify the apology strategy used in the workplace; and 3) to analyze the aspects which affect choices of expression and apology strategy. The qualitative research methodology was used, while the problem of research was viewed from the perspective of sociolinguistics. Source of the data in this research is a Japanese drama entitled Haken no Hinkaku (2007). In the drama, there are 78 (seventy-eight) apology expressions used in the workplace. The apology strategies are as follows: 1) directly apologizing; 2) providing explanation or stating the reason; 3) being responsible; 4) offering replacement of the damaged goods; and 5) making a promise to not repeat the same mistake.
\end{abstract}


Izumi, Volume 8 No 2, 2019

e-ISSN: 2502-3535 p-ISSN: 2338-249X

Tersedia online di http://ejournal.undip.ac.id/index.php/izumi

Furthermore, the aspects which play role in choosing expression and apology strategy are situation, degree of the mistake which was made, and the status of interlocutors.

Keywords: apology; apology expression; apology strategy; sociolinguistics.

\section{PENDAHULUAN}

Permintaan maaf didefinisikan
sebagai tindakan kompensasi atas
kesalahan yang telah diperbuat yang melibatkan pihak yang bersalah dan pihak yang dirugikan (Bergman \& Kasper dalam Kasper \& Blum-Kulka, 1993, p. 82). Dalam permintaan maaf yang ditekankan adalah pihak yang meminta maaf telah melakukan sesuatu yang bersifat mengganggu atau merugikan oang lain serta menyesali perbuatannya dan bertanggung jawab atas hal tersebut (Aijmer, 2014, p. 81). Holmes (1990, p. 161) mengemukakan beberapa kondisi yang harus diperhatikan dalam menganalisis permintaan maaf, yaitu: 1) tindakan; 2) keyakinan bahwa tindakan yang telah dilakukan tersebut merugikan orang lain; dan 3) bentuk tanggung jawab oleh pihak yang bersalah atas tindakan yang telah dilakukan.

Tata cara dalam meminta maaf berkaitan erat dengan budaya yang berlaku di suatu tempat. Dalam budaya Jepang, permintaan maaf merupakan hal yang tidak dapat dipisahkan dari kehidupan seharihari Kondo \& Taniguchi (2008, p. 148) menyatakan bahwa orang Jepang cenderung menerima permintaan maaf dengan penjelasan yang singkat. Penjelasan yang panjang dianggap kurang pantas karena pihak yang bersalah akan terlihat seperti meminimalisir tanggung jawab. Selain itu, permintaan maaf sebaiknya diiringi dengan introspeksi diri (hansei) di mana pihak yang bersalah berjanji tidak akan mengulangi kesalahan yang sama.

Masyarakat Jepang mengenal konsep uchi (in-group) dan soto (outgroup). Ini menandakan bahwa masyarakat Jepang berorientasi pada kelompok.
Menurut Tsuda (2003, p. 148) jika seorang individu berinteraksi dengan orang di luar kelompoknya, maka diharuskan untuk menunjukkan sikap formal dengan menaati norma atau etika yang berlaku (omote). Sebaliknya, ketika seorang individu berinteraksi dengan orang di dalam kelompoknya, maka individu tersebut dapat menunjukkan sikap informal yang bertentangan dengan norma atau etika yang berlaku (ura). Keempat konsep ini turut berperan dalam budaya permintaan maaf di Jepang.

Penelitian ini membahas tentang permintaan maaf di tempat kerja dalam drama Jepang. Drama yang digunakan berjudul Haken no Hinkaku (Nagumo, Sato, Shigeyama, \& Yoshino) yang tayang di NTV pada 2007 dan memperoleh rating $20,10 \%$ pada masa penayangannya. Drama ini menceritakan tentang seluk-beluk keberadaan haken di perusahaan Jepang. Haken merupakan pegawai tidak tetap yang mendapatkan pekerjaan melalui agensi di mana kontraknya berlaku selama 3 (tiga) bulan, tetapi dapat diperpanjang kembali selama perusahaan masih membutuhkan. Dalam drama ini terdapat banyak ungkapan permintaan maaf dengan konteks yang berbeda-beda, misalnya permintaan maaf antara pegawai tetap dengan pegawai tetap, antara haken dengan haken, antara haken dan pegawai tetap, dan sebagainya. Permintaan maaf yang muncul akan ditinjau dari perspektif sosiolinguistik.

Rumusan masalah yang diangkat dalam penelitian ini adalah: 1) ungkapan permintaan maaf yang digunakan di tempat kerja; 2) strategi yang digunakan ketika meminta maaf; dan 3) aspek-aspek yang mempengaruhi penggunaan ungkapan dan strategi permintaan maaf. Penelitian yang mengangkat tema permintaan maaf hingga 
saat ini masih sering dilakukan. Hal ini disebabkan permintaan maaf sulit untuk dikaji karena melibatkan berbagai aspek. Menurut Holmes (1990) aspek-aspek yang terlibat adalah kesantunan, jarak sosial, jenis kesalahan yang diperbuat (besar atau kecil), ungkapan permintaan maaf yang digunakan, dan kompensasi yang ditawarkan. Pernyataan ini diperkuat oleh pendapatJung (2004, p. 99), yaitu setiap masyarakat tutur (speech communities) memiliki perbedaan sudut pandang tentang perilaku yang dianggap menyinggung orang lain, ungkapan permintaan maaf seperti apa yang sesuai untuk digunakan, dan faktor-faktor kontekstual (status sosial, jarak sosial, dan bobot kesalahan) yang menjadi perhatian dalam masyarakat tersebut. Beberapa penelitian menggunakan data berupa ekspresi permintaan maaf yang diungkapkan oleh penutur asli, yaitu Shahrokhi \& Jan (2012), Bella (2014), Sari (2016), Abedi (2016), dan Li (2018). Selain itu, terdapat pula penelitian yang menggunakan data permintaan maaf yang diungkapkan oleh penutur asing atau pembelajar bahasa asing sebagai data, yaitu Salehi (2014), Saleem (2014), Ugla \& Abidin (2016), dan Keshani \& Heidari-Shahreza (2017). Pada umumnya, penelitian-penelitian tersebut membahas permintaan maaf yang digunakan dalam situasi yang bervariasi. Akan tetapi, melalui penelitian ini, penulis mengkhususkan pembahasan pada permintaan maaf yang dituturkan di tempat kerja.

Fokus utama yang menjadi pembahasan dalam sosiolinguistik adalah mempelajari pilihan bahasa yang digunakan oleh penutur (Edwards, 2013, p. 3). Dalam hal ini, dapat dilihat hubungan timbal balik di mana konteks mempengaruhi pilihan penggunaan bahasa. Penutur akan menggunakan bahasa yang berbeda ketika berbicara dengan pasangan, anak-anak, hewan peliharaan, dokter, pendeta, teman yang ditemui di bar, dan sebagainya. Variasi bahasa semacam ini dapat menjadi indikator penting terkait persepsi penutur terhadap situasi tertentu. Pilihan penggunaan bahasa berkisar dari makro hingga mikro (Bell, 2013). Ini berarti sosiolinguistik dapat digunakan untuk menganalisis pilihan penggunaan bahasa pada dua atau lebih bahasa yang berbeda atau menganalisis pelafalan yang berbeda dari konsonan yang sama dalam suatu bahasa.

Dalam perspektif sosiolinguistik, pembahasan terkait permintaan maaf lebih ditekankan pada strategi yang digunakan serta bentuk-bentuk ekspresi atau ungkapan dalam merealisasikan tindak tutur (Aijmer, 2014, p. 81). Selanjutnya, Holmes (1990, p. 159) mendeskripsikan permintaan maaf sebagai perilaku sosial, yaitu: "tindak tutur yang ditujukan kepada B untuk memperbaiki kesalahan yang menjadi tanggung jawab A, sehingga dapat mengembalikan keseimbangan dalam hubungan A dan B (di mana A sebagai pihak yang meminta maaf dan B sebagai pihak yang dirugikan).

Strategi permintaan maaf tidak terhitung jumlahnya dan bervariasi. Meskipun demikian, dapat diketahui strategi-strategi yang sering dipilih oleh orang ketika meminta maaf karena muncul berulang kali (Aijmer, 2014, p. 82). Cohen \& Olshtain (1981) mengklasifikasikan strategi permintaan maaf sebagai berikut:

1. Mengungkapkan permintaan maaf secara langsung

a. Ekspresi penyesalan (I'm sorry)

b. Menawarkan permintaan maaf (I apologize)

c. Memohon agar dimaafkan (excuse me/forgive me/pardon me)

2. Memberikan penjelasan atau alasan (there was a heavy traffic)

3. Menunjukkan sikap bertanggungjawab

a. Menyalahkan diri sendiri secara eksplisit (it's my mistake)

b. Menyatakan ketidaksengajaan (I didn't do it on purpose/I didn't mean it) 
c. Menunjukkan kekurangan diri sendiri (I totally forgot it/I didn't see you)

d. Menunjukkan bahwa merasa malu telah membuat kesalahan (I feel ashamed)

e. Mencela diri sendiri (It was very stupid of me)

f. Memahami

kemarahan/ketidaknyamanan lawan bicara (I understand that you are angry)

4. Menawarkan penggantian barang atau uang (I'll pay for the damage)

5. Berjanji tidak akan mengulangi kesalahan yang sama (It won't happen again)

Barnlud dan Yoshioka (dalam Gudykunst, 2004, p. 289) menyatakan bahwa terdapat bermacam-macam jenis strategi permintaan maaf yang digunakan oleh orang Jepang yang penggunaannya disesuaikan berdasarkan status lawan bicara. Dalam hal ini, strategi yang paling sering dipilih adalah menawarkan untuk melakukan sesuatu bagi lawan bicara. Ini berfungsi untuk menebus kesalahan yang telah diperbuat. Selain itu, orang Jepang lebih memilih untuk menggunakan permintaan maaf secara langsung (direct apology). Pendapat ini diperkuat oleh Kondo \& Taniguchi (2008, p. 142), yaitu orang Jepang menganggap bahwa meminta maaf dengan menunjukkan penyesalan adalah hal yang seharusnya dilakukan. Kondo \& Taniguchi (2008) melakukan survei terhadap 148 mahasiswa Jepang terkait permintaan maaf. Melalui hasil penelitiannya diketahui bahwa strategi mencela diri sendiri ketika meminta maaf dianggap tidak sesuai karena pihak yang membuat kesalahan akan terlihat seperti mengasihani dirinya sendiri dan tidak fokus pada kesalahan yang diperbuat. Selain permintaan maaf secara langsung, orang Jepang juga lebih menyukai jika pihak yang bersalah menjelaskan kesalahan yang telah diperbuat dan menyadari bahwa dirinya bertanggungjawab atas kesalahan tersebut. Beberapa ungkapan permintaan maaf dalam bahasa Jepang di antaranya adalah sumimasen, gomennasai, moushi wake arimasen, owabishimasu, dan go meiwaku kakemashita. Menurut Sugimoto (1998, p. 73), orang Jepang paling sering menggunakan sumimasen untuk meminta maaf karena merupakan ungkapan yang tergolong aman digunakan dalam berbagai situasi. Sumimasen sering digunakan dalam situasi formal dan informal untuk kesalahan yang bersifat ringan (Ishihara \& Maeda, 2010, p. 141). Gomennasai umumnya digunakan dalam situasi informal, misalnya pada keluarga atau teman. Selanjutnya, moushiwake arimasen merupakan ekspresi yang sangat formal dan lebih kuat dibandingkan dengan sumimasen. Ungkapan ini digunakan kepada orang yang memiliki kedudukan superior (Katyal, 2005, p. 94). Sebaliknya, moushi wake nai digunakan oleh superior ketika melakukan kesalahan kepada inferior. Ungkapan moushi wake gozaimasen memiliki tingkat/derajat kesopanan yang lebih tinggi dibandingkan moushi wake arimasen (Chigako, 2018). Moushi wake gozaimasen sering digunakan ketika menghadapi keluhan pelanggan. Akan tetapi, ekspresi ini tidak dianjurkan untuk diungkapkan berkali-kali karena akan menimbulkan kesan yang kurang baik. Dalam hal ini, dibandingkan meminta maaf berkali-kali, lebih baik jika permasalahan diselesaikan. Selanjutnya, owabishimasu digunakan jika kesalahan yang dibuat tergolong ke dalam kategori berat, misalnya ketika surat kabar menyampaikan informasi kurang tepat kepada pembaca dan go meiwaku kakemashita digunakan ketika melakukan sesuatu yang mengganggu orang lain (Ishihara \& Maeda, 2010, p. 141).

Tujuan penelitian adalah menjawab rumusan masalah, yaitu : 1) mengidentifikasi ungkapan permintaan maaf yang digunakan di tempat kerja; 2) 
Izumi, Volume 8 No 2, 2019

e-ISSN: 2502-3535 p-ISSN: 2338-249X

Tersedia online di http://ejournal.undip.ac.id/index.php/izumi

mengidentifikasi strategi permintaan maaf yang digunakan; dan 3) menganalisis aspek-aspek yang mempengaruhi pemilihan ungkapan dan strategi permintaan maaf. Melalui penelitian ini diharapkan agar pembaca dapat memperoleh informasi terkait budaya permintaan maaf di Jepang, khususnya di tempat kerja. Selain itu, pembaca juga dapat memperoleh pengetahuan terkait aplikasi konsep-konsep yang mengatur hubungan antar individu dan kelompok yang berlaku dalam masyarakat Jepang seperti uchi (in-group) dan soto (outgroup), ura (privat) dan omote (publik), dan jouge kankei (hubungan superiorinferior).

\section{METODE PENELITIAN}

Penelitian kualitatif merupakan penelitian yang bertujuan untuk menemukan motif-motif yang mendasari perilaku manusia (Kothari, 2009, p. 3). Melalui penelitian kualitatif dapat dianalisis berbagai faktor yang menyebabkan seseorang menunjukkan sikap tertentu. Oleh karena itu, penelitian kualitatif dianggap sesuai untuk menganalisis permintaan maaf di tempat kerja karena berkaitan dengan perilaku manusia.

Teknik pengumpulan data yang diterapkan adalah observasi. Data dikumpulkan dengan cara mengamati percakapan-percakapan yang terdapat dalam drama Haken no Hinkaku yang terdiri dari 10 (sepuluh) episode. Penulis menandai bagian-bagian di mana ungkapan permintaan maaf dituturkan oleh tokohtokoh yang terdapat dalam drama. Selanjutnya, penulis mencatat isi percakapan yang di dalamnya memuat ungkapan permintaan maaf. Data diklasifikasikan ke dalam beberapa bagian berdasarkan ungkapan permintaan maaf yang dituturkan, jenis kesalahan yang diperbuat, dan strategi yang digunakan. Data berupa ungkapan permintaan maaf yang dituturkan oleh tokoh-tokoh drama dengan latar tempat bukan di tempat kerja akan dieliminasi. Selanjutnya, pada tahap analisis data, penulis memaparkan keterkaitan antara ungkapan permintaan maaf, strategi yang digunakan serta aspekaspek yang mempengaruhi penggunaan ungkapan dan strategi permintaan maaf.

\section{HASIL DAN PEMBAHASAN}

Berikut akan dipaparkan dalam tabel 1, ekspresi atau ungkapan permintaan maaf yang ditemukan dalam drama Haken no Hinkaku. Ditemukan 23 (dua puluh tiga) ungkapan permintaan maaf yang berbeda-beda yang digunakan di tempat kerja. Berdasarkan hasil observasi diketahui bahwa ungkapan permintaan maaf yang digunakan disesuaikan dengan situasi, bobot kesalahan yang diperbuat, dan status lawan bicara (berkaitan dengan tingkat kesopanan).

\section{Tabel 1 Ekspresi Ungkapan Permintaan} Maaf

\begin{tabular}{|c|c|c|}
\hline No. & Ekspresi Permintaan Maaf & Jumlah \\
\hline 1. & すみません sumimasen & 28 \\
\hline 2. & $\begin{array}{l}\text { すみませんでした } \\
\text { sumimasendeshita }\end{array}$ & 3 \\
\hline 3. & すいません suimasen & 5 \\
\hline 4. & すまんすまん suimasen & 1 \\
\hline 5. & ごめんなさい gomennasai & 4 \\
\hline 6. & ごめんね gomenne & 2 \\
\hline 7. & ごめんな gomenna & 1 \\
\hline 8. & $\begin{array}{l}\text { 申し訳ありません } \\
\text { moushiwakearimasen }\end{array}$ & 9 \\
\hline 9. & $\begin{array}{l}\text { 申し訳ありませんでした } \\
\text { Moushiwakearimasendeshita }\end{array}$ & 3 \\
\hline 10. & $\begin{array}{l}\text { 本当に申し訳ありません } \\
\text { Hontouni } \\
\text { moushiwakearimasen }\end{array}$ & 3 \\
\hline 11. & $\begin{array}{l}\text { 本当に申し訳ありませんで } \\
\text { した } \\
\text { Hontouni } \\
\text { moushiwakearimasendeshita }\end{array}$ & 1 \\
\hline 12. & $\begin{array}{l}\text { 大変申し訳ありません } \\
\text { Taihen moushiwakearimasen }\end{array}$ & 3 \\
\hline 13. & $\begin{array}{l}\text { 大変申し訳ありませんでし } \\
\text { た } \\
\text { Taihen } \\
\text { moushiwakearimasendeshita }\end{array}$ & 1 \\
\hline
\end{tabular}


Izumi, Volume 8 No 2, 2019

e-ISSN: 2502-3535 p-ISSN: 2338-249X

Tersedia online di http://ejournal.undip.ac.id/index.php/izumi

\begin{tabular}{|c|c|c|}
\hline 14. & $\begin{array}{l}\text { 申し訳ない } \\
\text { Moushiwakenai }\end{array}$ & 1 \\
\hline 15. & $\begin{array}{l}\text { 申し訳ございません } \\
\text { Moushiwakegozaimasen }\end{array}$ & 7 \\
\hline 16. & $\begin{array}{l}\text { 申し訳ございませんでした } \\
\text { Moushiwakegozaimasen } \\
\text { deshita }\end{array}$ & 1 \\
\hline 17. & $\begin{array}{l}\text { 申し訳ございます } \\
\text { Moushiwakegozaimasu }\end{array}$ & 2 \\
\hline 18. & $\begin{array}{l}\text { 本当に申し訳ございません } \\
\text { でした } \\
\text { Hontouni } \\
\text { Moushiwakegozaimasendeshita }\end{array}$ & 1 \\
\hline 19. & $\begin{array}{l}\text { まことに申し訳ございませ } \\
\text { んでした } \\
\text { Makoto ni } \\
\text { moushiwakegozaimasendeshita }\end{array}$ & 2 \\
\hline 20. & $\begin{array}{l}\text { 申し訳ございます } \\
\text { Moushiwakegozaimasu }\end{array}$ & 2 \\
\hline 21. & $\begin{array}{l}\text { 私は悪うございました } \\
\text { Watashi wa waruu } \\
\text { gozaimashita }\end{array}$ & 1 \\
\hline 22. & $\begin{array}{l}\text { お詫びに上がりました } \\
\text { Owabi ni agarimashita }\end{array}$ & 1 \\
\hline 23. & $\begin{array}{l}\text { 失礼いたしました } \\
\text { Shitsureiitashimashita }\end{array}$ & 1 \\
\hline & Total & 78 \\
\hline
\end{tabular}

Sumber: Drama Haken no Hinkaku (2007) Episode 1-10

Ungkapan sumimasen paling banyak ditemukan dalam situasi formal dan informal. Selain itu, moushi wake arimasen dan moushi wake gozaimasen berikut variasinya juga banyak ditemukan karena di tempat kerja sering muncul situasi formal yang mengharuskan penutur menggunakan ungkapan tersebut. Ungkapan permintaan maaf yang diungkapkan oleh para tokoh dalam drama yang di antaranya berperan sebagai: 1) Haken (pegawai tidak tetap pada suatu perusahaan); 2) Seishain (pegawai tetap suatu perusahaan); 3) Buchou (kepala bagian suatu perusahaan); 4) Kaichou/Shachou (direktur perusahaan); dan 4) Manajer agensi haken. Selanjutnya, dalam subbab berikut akan dijelaskan secara rinci ungkapan permintaan maaf yang muncul dan jenis-jenis kesalahan yang diperbuat.

\section{Ungkapan Permintaan Maaf dan Bentuk-bentuk Kesalahan yang diperbuat}

Pada bagian ini diklasifikasikan ungkapan permintaan maaf berdasarkan kesalahan yang diperbuat. Selain itu, dicantumkan pula pihak yang bersalah (yang meminta maaf) dan pihak yang dirugikan. Secara sederhana, hubungan antara pihak yang bersalah dan pihak yang dirugikan dapat digambarkan sebagai berikut:

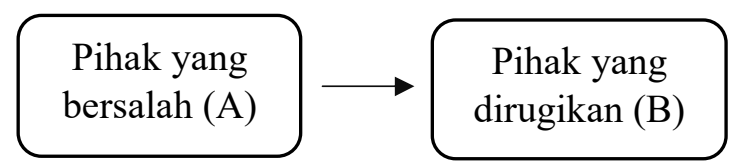

Keterangan :

Pihak yang bersalah (A) meminta maaf kepada pihak yang dirugikan (B)

Ungkapan sumimasen digunakan oleh laki-laki kepada perempuan dan sebaliknya. Begitu juga dengan variasinya, yaitu suimasen. Akan tetapi, suman suman digunakan oleh laki-laki kepada laki-laki. Dalam drama ini, ekspresi ini digunakan kepada sesama rekan kerja yang hubungannya sudah akrab (sudah berteman sejak mahasiswa). Berikut ini bentukbentuk kesalahan yang diperbuat di mana ungkapan sumimasen berikut variasinya digunakan:

1. Haken yang ditempatkan di suatu divisi menolak untuk mengerjakan pekerjaan yang seharusnya menjadi tanggung jawab divisi lain (pegawai tetap $\rightarrow$ pegawai tetap)

2. Belum menyelesaikan pekerjaan yang diminta (haken $\rightarrow$ pegawai tetap)

3. Menumpahkan kekesalan di dekat rekan kerja (pegawai tetap $\rightarrow$ pegawai tetap)

4. Merusak mesin pembuat kopi (haken $\rightarrow$ pegawai tetap) 
Izumi, Volume 8 No 2, 2019

e-ISSN: 2502-3535 p-ISSN: 2338-249X

Tersedia online di http://ejournal.undip.ac.id/index.php/izumi

5. Membuat haken lain merasa tidak nyaman karena menyanggupi untuk membelikan kopi dan rokok untuk pegawai tetap (haken $\rightarrow$ haken)

6. Menolak ajakan untuk makan siang bersama (haken $\rightarrow$ haken)

7. Bau parfum yang dikenakan membuat pegawai lain tidak nyaman (haken $\rightarrow$ haken)

8. Menghalangi jalan karena mengobrol (pegawai tetap $\rightarrow$ haken)

9. Pegawai tetap merasa tidak nyaman karena haken memiliki kemampuan yang lebih tinggi dibandingkan dirinya (manajer agensi haken $\rightarrow$ pegawai tetap)

10. Tidak sengaja menyenggol tumpukan dokumen penting ketika lewat (haken $\rightarrow$ pegawai tetap)

11. Berbohong tidak masuk kerja dengan alasan Ibu jatuh sakit (haken $\rightarrow$ pegawai tetap)

12. Tidak serius ketika diajari cara menggunakan komputer (pegawai tetap $\rightarrow$ haken)

13. Makan pada saat jam kerja berlangsung (pegawai tetap $\rightarrow$ haken)

14. Lupa memberi izin makan siang kepada haken yang bekerja di divisinya karena sebelumnya memberi tugas hingga melewati jam makan siang (pegawai tetap $\rightarrow$ haken)

15. Merasa tidak dapat membantu orang lain (pegawai tetap $\rightarrow$ pegawai tetap)

16. Haken yang akan diperbantukan di perusahaan berlaku kurang sopan (manajer agensi haken $\rightarrow$ pegawai tetap)

17. Status sebagai haken dianggap tidak bisa menyelesaikan masalah (haken $\rightarrow$ pimpinan perusahaan mitra)

18. Tidak dapat mengatur para haken yang diperbantukan sementara waktu di perusahaan (haken $\rightarrow$ pegawai tetap)

19. Menolak ajakan makan malam (pegawai tetap $\rightarrow$ haken)

20. Dengan sengaja melihat tanggal lahir yang tertera di kartu identitas yang tersimpan di dalam tas yang tertinggal (pegawai tetap $\rightarrow$ haken)
21. Mengganggu konsentrasi buchou (kepala bagian) yang sedang menyusun kartu nama perusahaan mitra (pegawai tetap $\rightarrow$ buchou)

22. Proposal yang disusun lolos seleksi dan akan direalisasikan, sehingga pegawai tetap merasa tersinggung dan tidak ingin mengerjakan project yang diusulkan oleh haken (haken $\rightarrow$ pegawai tetap)

23. Menangis di dalam bilik toilet karena dimarahi oleh pegawai tetap (haken $\rightarrow$ haken) dan (haken $\rightarrow$ manajer agensi haken)

24. Menghidupkan HP selama jam kerja berlangsung (haken $\rightarrow$ haken)

25. Perlakuan kohai (junior) yang kurang sopan terhadap haken (pegawai tetap $\rightarrow$ haken)

26. Tanggal penjualan haken bentou tidak bisa dimajukan karena merupakan kebijakan perusahaan (pegawai tetap $\rightarrow$ haken)

27. Salah seorang haken memperpanjang kontraknya di perusahaan, sedangkan haken lain tidak (haken $\rightarrow$ haken)

28. Sudah banyak merepotkan selama 3 (tiga) bulan bekerja (haken $\rightarrow$ pegawai tetap)

Ungkapan gommennasai berikut variasinya (gomenne dan gomenna) bersifat tidak formal dan digunakan kepada orang yang memiliki hubungan dekat. Dalam drama diketahui bahwa ungkapan ini digunakan pada rekan kerja yang seumuran, atasan kepada bawahan yang bekerja di divisi yang sama, dan kepada anak kecil. Jika dilihat berdasarkan gender, gomennasai digunakan oleh perempuan kepada perempuan dan laki-laki kepada perempuan. Berikut ini merupakan bentukbentuk kesalahan di mana ungkapan gomennasai, gomenne, dan gomenna digunakan:

1. Menolak untuk makan siang bersama kelompok/geng haken perempuan karena kelompok tersebut selalu memilih restoran yang mahal (haken $\rightarrow$ haken) 
2. Meminta maaf kepada atasan karena berbohong tidak masuk kerja dengan alasan ibu sakit, padahal sebenarnya mengikuti wawancara di perusahaan lain (haken $\rightarrow$ pegawai tetap)

3. Menolak pernyataan suka yang dinyatakan oleh haken (pegawai tetap $\rightarrow$ haken)

4. Membuat anak orang lain menangis karena mengeluarkan suara yang keras (haken $\rightarrow$ anak kecil)

5. Meminta maaf mewakili buchou (kepala bagian) karena harus membatalkan kontrak haken yang masih berlaku (pegawai tetap $\rightarrow$ manajer agensi haken)

6. Meminta maaf kepada haken karena project yang disusun oleh haken tersebut diambil alih oleh divisi lain (pegawai tetap $\rightarrow$ haken)

7. Meminta maaf kepada rekan kerja karena menuruti perintah atasan untuk mengambil alih project yang seharusnya ditangani oleh divisi rekan kerja (pegawai tetap $\rightarrow$ pegawai tetap)

Ungkapan moushi wake arimasen memiliki arti iiwake dekinai, yaitu tidak ada alasan yang dapat dikemukakan atas kesalahan yang telah diperbuat. Ini berarti pihak yang bersalah mengakui telah merugikan orang lain atau membuat orang lain merasa tidak nyaman. Dalam drama, ekspresi moushi wake arimasen pada umumnya dinyatakan kepada atasan, pelanggan, dan perusahaan mitra. Selain itu, juga ditemukan pada situasi di mana atasan meminta maaf kepada bawahan. Menurut Chigako (2018), ekspresi ini digunakan pada bijinesu siin atau situasi yang berkaitan dengan pekerjaan. Berikut ini situasi-situasi di mana moushiwake arimasen dan variasinya digunakan:

1. Meninggalkan dokumen penting perusahaan di dalam taksi (haken $\rightarrow$ pegawai tetap)

2. Mendengar kabar bahwa taksi yang berisi dokumen penting mengalami kecelakaan, sehingga akan dihancurkan (haken $\rightarrow$ pegawai tetap)

3. Mengakui bahwa selama ini dirinya telah membuat kesalahan karena tidak menghargai pegawai tetap (haken $\rightarrow$ pegawai tetap)

4. Tidak sengaja menumpahkan teh dan mengenai baju pegawai tetap yang sedang rapat (haken $\rightarrow$ pegawai tetap)

5. Meminta maaf kepada para pelanggan yang sudah datang untuk menyaksikan pertunjukan padahal bintang tamu berhalangan hadir karena sakit (pegawai tetap dan haken $\rightarrow$ pelanggan departement store)

6. Kepala divisi mewakili buchou (kepala bagian) untuk menyampaikan bahwa kontrak pegawai tetap tersebut tidak dapat diperpanjang (pegawai tetap $\rightarrow$ pegawai tetap)

7. Meminta maaf karena haken dari agensinya disangka melakukan perbuatan yang tidak sopan (menyeret dengan menggunakan dasi) kepada salah seorang pegawai tetap (manajer agensi haken $\rightarrow$ pegawai tetap)

8. Meminta maaf karena haken yang bekerja di perusahaannya tidak melakukan pekerjaan dengan benar (pegawai tetap $\rightarrow$ pemilik perusahaan mitra)

9. Meminta maaf karena cokelat yang diproduksi oleh perusahaan mitra tidak laku terjual di hari itu karena sebuah insiden (haken $\rightarrow$ pemilik perusahaan mitra)

10. Meminta maaf kepada buchou (kepala bagian) karena cokelat yang diproduksi oleh perusahaan mitra tidak laku terjual (pegawai tetap $\rightarrow$ kepala bagian)

11. Meminta maaf di hadapan tim penilai project perusahaan karena tidak dapat mempresentasikan proposal yang sebenarnya disusun oleh divisi lain (pegawai tetap $\rightarrow$ tim penilai project)

12. Meminta maaf karena tidak bisa menjaga anjing yang dititipkan kepadanya (haken $\rightarrow$ calon pegawai tetap) 
Izumi, Volume 8 No 2, 2019

e-ISSN: 2502-3535 p-ISSN: 2338-249X

Tersedia online di http://ejournal.undip.ac.id/index.php/izumi

13. Meminta maaf karena ucapan sudah menyinggung orang lain yang ada di ruangan itu (calon pegawai tetap $\rightarrow$ pegawai tetap dan haken)

14. Meminta maaf karena tidak jadi memperpanjang kontrak kerja, padahal sebelumnya berkata sebaliknya (manajer agensi haken/haken $\rightarrow$ manajer divisi)

Moushiwake gozaimasen tingkat kesopanannya lebih tinggi dibandingkan moushiwake arimasen, di mana gozaru merupakan teineigo 'bentuk sopan' dari aru. Dalam drama, ekspresi ini dinyatakan oleh bawahan kepada atasan, manajer agensi haken kepada pegawai tetap, dan pegawai tetap/haken kepada perusahaan mitra. Selain itu, juga diketahui bahwa ekspresi ini juga dapat digunakan pada situasi yang sama di mana ungkapan moushiwake arimasen juga digunakan. Dalam hal ini, moushiwake gozaimasen diungkapkan terlebih dahulu baru kemudian permintaan maaf diulangi kembali dengan menyatakan moushi wake arimasen. Ungkapan ini diikuti dengan saikeirei 'membungkukkan badan 45 (empat puluh lima) derajat' atau berlutut. Berikut ini merupakan situasi-situasi di mana moushi wake gozaimasen berikut variasinya digunakan:

1. Meminta maaf mewakili pegawai tetap karena salah mengukur luas tempat penjualan (haken $\rightarrow$ manajer departement store)

2. Meminta maaf kepada salah satu manajer departement store (soto no mono) karena belum menemukan pengganti bintang tamu yang seharusnya mengisi acara esok hari (pegawai tetap $\rightarrow$ manajer departement store)

3. Meminta maaf kepada pengunjung departement store karena terpaksa membatalkan pertunjukkan akibat bintang tamu mengalami kecelakaan (Seluruh staf perusahaan $\rightarrow$ pengunjung/pelanggan departement store)
4. Meminta maaf karena haken yang berasal dari agensinya diduga melakukan perbuatan yang kurang sopan kepada salah satu pegawai tetap (manajer agensi haken $\rightarrow$ pegawai tetap)

5. Meminta maaf karena tidak tahu bahwa lawan bicara merupakan pemilik perusahaan mitra (haken $\rightarrow$ pemilik perusahaan mitra)

6. Meminta maaf kepada kepala bagian karena akibat perbuatannya, cokelat yang diproduksi perusahaan mitra tidak laku terjual (haken $\rightarrow$ kepala bagian)

7. Meminta maaf kepada pemilik perusahaan mitra karena insiden yang terjadi menyebabkan cokelat yang diproduksi tidak laku terjual (pegawai tetap/haken $\rightarrow$ pemilik perusahaan mitra)

8. Meminta maaf karena rekan kerja tidak mengenali pimpinan perusahaan (pegawai tetap $\rightarrow$ pemimpin perusahaan)

Ungkapan watashi wa waruugozaimasu yang memiliki arti 'saya mengakui kesalahan yang telah saya perbuat' hanya diungkapkan 1 (satu) kali di dalam drama. Ungkapan ini jarang digunakan karena tergolong ke dalam furui iikata 'ungkapan yang digunakan oleh orang-orang pada masa lalu'. Berikut ini merupakan situasi di mana ungkapan ini dituturkan:

Meminta maaf kepada pegawai tetap karena selama ini tidak menjalankan perintah pegawai tetap lain selain kepala divisi tempatnya bekerja (haken $\rightarrow$ pegawai tetap)

Ungkapan owabi ni agarimashita 'saya datang untuk meminta maaf' juga muncul 1 (satu) kali saja di dalam drama. Sebelum menuturkan ungkapan ini, pihak yang bersalah menyerahkan oleh-oleh (tsumaranai mono) kepada pihak yang dirugikan. Selanjutnya diikuti dengan saikeirei 'membungkukkan badan 45 
Izumi, Volume 8 No 2, 2019

e-ISSN: 2502-3535 p-ISSN: 2338-249X

Tersedia online di http://ejournal.undip.ac.id/index.php/izumi

derajat' untuk menunjukkan bahwa dirinya benar-benar merasa bersalah. Berikut ini merupakan situasi di mana ekspresi ini digunakan:

Meminta maaf kepada kepala bagian karena haken yang berasal dari agensinya tidak sengaja merusakkan mesin pembuat kopi yang ada di kantor (manajer agensi haken $\rightarrow$ kepala bagian)

Ungkapan shitsurei itashimashita 'maaf saya telah berbuat kurang sopan' hanya diungkapkan 1 (satu) kali oleh pemeran dalam drama ini. Ungkapan ini dituturkan dengan diikuti oleh saikeirei. Selain itu, rekan kerja yang kebetulan berada di sana juga ikut meminta maaf atas kesalahan temannya dengan menyatakan moushi wake gozaimasen. Berikut ini merupakan situasi di mana ungkapan ini dituturkan:

Meminta maaf kepada pimpinan perusahaan (kaichou) karena tidak mengenali wajahnya (pegawai tetap $\rightarrow$ pimpinan perusahaan)

\section{Strategi Permintaan Maaf yang Digunakan}

Pada bagian ini dijelaskan strategi yang digunakan dalam meminta maaf di tempat kerja yang ditemukan dalam sumber data. Penulis menemukan 5 (lima) strategi yang dikemukakan oleh Cohen \& Olshtain, (1981). Berikut ini dipaparkan jenis-jenis strategi yang digunakan berikut contohnya (teks Jepang seluruhnya dikutip dari dramanote.com).

1. Mengungkapkan permintaan maaf secara langsung

Berdasarkan observasi penulis, permintaan maaf secara langsung diungkapkan ketika pihak yang bersalah tidak memiliki pembelaan atas kesalahan yang telah diperbuat atau tidak memiliki solusi untuk menyelesaikan masalah. Ungkapan permintaan maaf yang digunakan bersama dengan strategi ini juga bervariasi. Lebih jelasnya, strategi meminta maaf secara langsung dapat dilihat pada data berikut ini:

\section{Data 1}

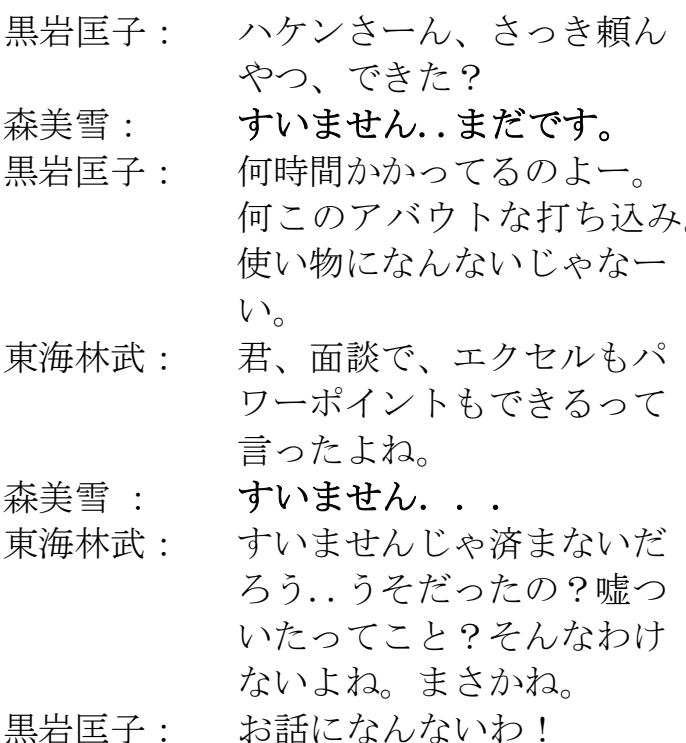

Terjemahan

Kuroiwa Masako:

Haken-san, apa dokumen yang saya minta untuk dikerjakan tadi sudah selesai?

Mori Miyuki:

Maaf, belum selesai saya kerjakan.

Kuroiwa Masako:

Lama sekali ya...(sambil mengecek ketikan). Mengapa ketikanmu acak-acakan seperti ini? Kalau seperti ini tidak bisa digunakan.

Mori Miyuki:

Maaf....

Shouji Takeshi:

Meminta maaf tidak akan menyelesaikan masalah. Kamu berbohong ya? Pada waktu wawancara bukankah kamu bilang kalau kamu dapat mengoperasikan microsoft office?

Kuroiwa Masako:

Buang-buang waktu saja.

\section{(Haken no Hinkaku, Episode 1)}

\section{Data 2}

里中賢介： みなさん、八ケン弁当の発 売日が決まりました。2007 年度上期の、スタートダッ 
Izumi, Volume 8 No 2, 2019

e-ISSN: 2502-3535 p-ISSN: 2338-249X

Tersedia online di http://ejournal.undip.ac.id/index.php/izumi

\begin{tabular}{|c|c|c|}
\hline & & $\begin{array}{l}\text { シュとして、4月 } 2 \text { 日月曜 } \\
\text { 日になりました。 } \\
\text { カレンダーを見つめる美雪 } \\
\text { の表情が曇る。 }\end{array}$ \\
\hline 浅野務 & : & $\begin{array}{l}4 \text { 月じゃ、森ちゃんと大さ } \\
\text { んはいないかも・・近が自 } \\
\text { 分も、と指を指す。 }\end{array}$ \\
\hline 大前春子： & & $\begin{array}{l}\text { かもではなく、私は い ま } \\
\text { せん！ }\end{array}$ \\
\hline 浅野務 & : & $\begin{array}{l}\text { 主任、発売日、もう少し早 } \\
\text { められないんですか? }\end{array}$ \\
\hline 小笠原繁： & & $\begin{array}{l}\text { 会社の方針で決まっちやっ } \\
\text { たんじや、しょうがないや } \\
\text { ね。 }\end{array}$ \\
\hline 森美雪 : & & そうですよ。 \\
\hline 里中賢介： & & ・・・すみません。 \\
\hline 大前春子： & & $\begin{array}{l}\text { そんなことより、コストの } \\
\text { 問題はクリア出来るんです } \\
\text { か! ? }\end{array}$ \\
\hline 里中賢介： & & $\begin{array}{l}\text { 現状では } 500 \text { 円で販売した } \\
\text { ら赤字です。へルシーな食 } \\
\text { 材と、玄米や白米の美味し } \\
\text { さにこだわると、どうして } \\
\text { も } 600 \text { 円はかかってしまい } \\
\text { ます。でも、そこを何とか } \\
\text { しいんです。 }\end{array}$ \\
\hline
\end{tabular}

Terjemahan

Satonaka Kensuke:

Perhatian semuanya, hari penjualan haken bento sudah ditentukan, yaitu tepatnya pada 2 April 2007.

(Miyuki memandang kalender dengan wajah murung)

Asano Tsutomu:

Kalau April, mungkin Mori-chan dan Oomae-san sudah tidak bekerja di sini lagi...

(Kon menunjuk dirinya sendiri, menandakan bahwa kontraknya juga habis pada bulan April)

Oomae Haruko:

Bukan mungkin...saya sudah pasti tidak bekerja di sini lagi.

Asano Tsutomu:

Pak Manajer, apa hari penjualan tidak bisa dimajukan jadi lebih cepat?

Ogasawara Shigeru:

Apa boleh buat karena ini merupakan kebijakan perusahaan.

\begin{abstract}
Mori Miyuki:
Benar.

Satonaka Kensuke:

Maaf ya...

Oomae Haruko:

Ada hal yang lebih penting dibandingkan ini, apakah masalah biaya sudah terpecahkan?

Satonaka Kensuke:

Jika menjual haken bento seharga 500 yen, maka akan rugi. Terlebih jika ingin membuat dengan bahan-bahan yang sehat dan beras yang bagus. Bagaimanapun juga harga minimal adalah 600 yen. Akan tetapi, saya akan mencoba melakukan sesuatu (supaya harga bento tidak melebihi 500 yen).
\end{abstract}

\section{(Haken no Hinkaku, Episode 10)}

Pada data 1, Mori Miyuki diminta oleh Kuroiwa Masako untuk menyusun data dengan menggunakan microsoft excel. Akan tetapi, Mori tidak dapat menyelesaikan pekerjaan tepat waktu dan hasil ketikannya tidak rapi. Pada situasi ini, strategi meminta maaf secara langsung digunakan di mana Mori tidak bisa membela dirinya karena memang tidak memiliki kemampuan dalam mengoperasikan komputer. Selanjutnya, pada data 2, Satonaka Kensuke meminta maaf karena tidak dapat berbuat apa-apa terkait tanggal penjualan haken bento yang sudah ditentukan perusahaan. Sebagai pegawai di perusahaan itu dirinya hanya bisa mengikuti kebijakan perusahaan. Dalam hal ini, meskipun tidak melakukan kesalahan, Satonaka meminta maaf karena para haken yang bekerja di divisinya tidak dapat hadir dalam peluncuran produk karena kontrak kerja yang berakhir.

2. Memberikan penjelasan atau alasan

Pada strategi ini, selain menggunakan ekspresi permintaan maaf, pihak yang bersalah memberikan alasan mengapa hal tersebut dilakukan. Dari data yang terkumpul memang terlihat bahwa orang Jepang meminta maaf diiringi dengan penjelasan yang singkat (Kondo \& 
Izumi, Volume 8 No 2, 2019

e-ISSN: 2502-3535 p-ISSN: 2338-249X

Tersedia online di http://ejournal.undip.ac.id/index.php/izumi

Taniguchi, 2008, p. 148). Beberapa alasan yang diberikan ketika meminta maaf adalah tidak bisa/tidak ada solusi, tidak tahu, tidak teliti dan tidak sengaja. Selain itu, juga terdapat alasan yang bersifat personal yang diungkapkan ketika menolak ajakan orang lain. Berikut ini merupakan contoh situasi di mana strategi meminta maaf dengan memberikan penjelasan atau alasan digunakan:

\section{Data 3}

仕事中おにぎりにかぶりつく浅野。春子 が睨みつける。

浅野務： すみません。寝坊して朝飯 食いそびれちゃって。

小笠原繁： カニマヨネーズ? 何でこん な変な具を入れるのかねー。 おにぎりは、塩むすびが一 番!

森美雪： あ、うちのおじいちゃんも 塩むすび大好きです!

近耕作：僕も好きです！

\section{Terjemahan}

Asano sedang mengunyah onigiri (nasi kepal) ketika jam kerja berlangsung. Melihat itu, Haruko melotot kepadanya.

Asano Tsutomu:

Maaf. Saya tadi ketiduran, sehingga tidak sempat sarapan.

Ogasawara Shigeru:

Kepiting mayonais? Mengapa isian onigiri aneh seperti ini? Padahal shio musubi yang paling pas!

Mori Miyuki:

Ah...kakek saya juga menyukai onigiri dengan isian shio musubi.

Kon Kousaku:

Saya juga suka!

\section{(Haken no Hinkaku, Episode 5)}

\section{Data 4}

最終プレゼンが始まる。

東海林の企画が一番最初に発表する。

名前を呼ばれてもなかなか立ち上がらな

い東海林。

やっと前に出た東海林は・・・
東海林：・・・申し訳ありませんが

僕にはプレゼン出来ません。 ハケン弁当は、僕の企画で

はないからです。

桐島敏郎： 東海林、何言ってんだ。撤 回しろ!

東海林：・・・お断りします、 部長。

東海林主任、ちゃんと説明して下さい!

東海林：・・・この企画は、 里中賢介と、マーケティン グ課の企画です！

\section{Terjemahan}

Presentasi penentuan akan dimulai. Shouji Takeshi mendapat giliran presentasi pertama. Akan tetapi, meskipun namanya dipanggil Shouji tidak bergerak dari tempat duduknya.

Akhirnya, Shouji maju ke depan.

Shouji Takeshi:

Saya minta maaf karena tidak bisa presentasi. Hal ini karena bukan saya yang menyusun proposal haken bento.

Kirishima Toshio:

Shouji Takeshi! Apa yang kamu bilang barusan? Tarik kembali kata-katamu!

Tim Penilai:

Manajer Shouji mohon jelaskan!

Shouji Takeshi:

Proposal ini merupakan hasil karya Satonaka Kensuke dan rekan-rekan dari Divisi Marketing!

\section{(Haken no Hinkaku, Episode 8)}

Pada data 3, Asano meminta maaf karena makan onigiri pada saat jam kerja berlangsung. Dalam hal ini, Asano memberikan alasan bahwa dirinya ketiduran, sehingga tidak sempat sarapan pagi. Selanjutnya, pada data 4, Shouji Takeshi meminta maaf karena tidak bisa presentasi di hadapan tim penilai karena proposal yang akan dipresentasikan bukan merupakan hasil karyanya. Situasi ini bersifat formal, sehingga Shouji menggunakan ungkapan moushiwake arimasen diikuti dengan penjelasan bahwa 
Izumi, Volume 8 No 2, 2019

e-ISSN: 2502-3535 p-ISSN: 2338-249X

Tersedia online di http://ejournal.undip.ac.id/index.php/izumi

proposal tersebut disusun oleh rekan-rekan dari Divisi Marketing.

3. Menunjukkan sikap bertanggung jawab

Sikap bertanggungjawab merupakan salah satu strategi yang digunakan agar pihak yang bersalah dapat dimaafkan oleh pihak yang dirugikan. Berdasarkan pengamatan penulis, bertanggungjawab merupakan salah satu bentuk kesungguhan yang ditunjukkan oleh pihak yang bersalah untuk memperbaiki keadaan. Khususnya, pada jenis kesalahan yang tergolong berat. Berikut ini merupakan situasi di mana meminta maaf dengan strategi menunjukkan sikap bertanggungjawab digunakan:

\section{Data 5}

$$
\begin{aligned}
& 9 \text { 時のチャイムが鳴る。 } \\
& \text { 森美雪： あ！・・・どうしよう。 } \\
& \text { 美雪が立ち上がる。 } \\
& \text { 里中賢介：＼cjkstart森君、どうした? } \\
& \text { 森美雪： あ、あの、あの・・・ } \\
& \text { プレゼンの、打ち込みを } \\
& \text { した資料、タクシーの中 } \\
& \text { に・・ } \\
& \text { 浅野務：置き忘れた！? } \\
& \text { 森美雪：日領収書ももらってな } \\
& <、 \\
& \text { どこのタクシー会社かもわ } \\
& \text { からない。 }
\end{aligned}
$$

里中賢介：落ち着いて。会議は明日の 朝一だから、急いで打ち直 せば間に合うよ。データの ディスクは?

$\begin{array}{ll}\text { 森美雪： } & \text { あ・・・あの・・・ } \\ & \text { それも、一緒に、紙袋に入 } \\ & \text { れて、置いてきちゃったん } \\ & \text { です。 } \\ \text { みんな : } & \text { えーーーっ! ? } \\ \text { 森美雪： } & \text { あの、本当に申し訳ありま } \\ & \text { せん。急いで探してきま } \\ & \text { す! }\end{array}$

美雪がオフィスを飛び出していく。

\section{Terjemahan}

Jam menunjukkan pukul 9 pagi.

Mori Miyuki:

Waduh...gawat!
Satonaka Kensuke:

Mori-kun, ada apa?

Mori Miyuki:

Itu..itu...data yang sudah saya ketik, yang

akan digunakan untuk presentasi, ketinggalan di dalam taksi.

Asano Tsutomu:

Apa? Ketinggalan di dalam taksi!?

Mori Miyuki:

Tadi saya juga tidak mengambil struknya, sehingga saya tidak tahu perusahaan taksinya.

Satonaka Kensuke:

Tenang dulu. Rapatnya masih besok pagi, kalau kita segera mengetik ulang data pasti bisa selesai. CD tempat data itu disimpan ada bukan?

Mori Miyuki:

Waduh...itu juga saya masukkan di dalam kantong dan tertinggal di dalam taksi.

Seluruh anggota Divisi Marketing:

Apa....!?

Mori Miyuki:

Saya sungguh-sungguh minta maaf, saya akan segera mencarinya!

Setelah mengatakan itu, Mori Miyuki berlari keluar dari kantor.

\section{(Haken no Hinkaku, Episode 1)}

\section{Data 6}

=シルスマリオ $=$

東海林：申訳ありません！ 売れ残ったチョコレートは、 決して無駄にはいたしませ ん!

大前春子： まことに申し訳ございませ んでした!

土下座する東海林と春子。

橋立社長：今取り込んでいるから帰っ てください。 新製品の話 は白紙ということで。

東海林： ちょ、それだけは、 この通りです!

そこへ、アユミがやって来た。苦しそう にお腹を押さえている。

橋立社長：あんたが徹夜なんかさせる から!この人、上の子の時 も早かったのよ!

東海林：申し訳ございません！！ 


\section{橋立社長： 大丈夫? 車まで歩ける? \\ アユミ：産まれる・・・ \\ 橋立社長： いきんじゃだめ! \\ いきんじゃだめよ！ \\ アユミ： お母さん、もうダメ！ \\ 橋立社長：救急車を呼んで！！}

\section{Terjemahan}

Shouji Takeshi:

Kami minta maaf! Cokelat yang tidak terjual pasti tidak akan kami sia-siakan.

Oomae Haruko:

\section{Kami sungguh-sungguh minta maaf.}

Shouji dan Haruko meminta maaf sambil berlutut.

Direktur Hashidate:

Sekarang kami sedang sibuk, jadi tolong kalian pulang saja. Pembicaraan mengenai produk baru dibatalkan saja.

Shouji Takeshi:

Mengenai hal itu...mohon diteruskan seperti rencana semula.

Setelah itu, Ayumi (anak perempuan Direktur Hashidate) yang sedang hamil keluar sambil memegangi perutnya yang sakit.

Direktur Hashidate:

Ini karena kalian memaksanya bekerja sampai larut malam untuk membuat cokelat! Akibatnya anak pertamanya akan lahir lebih cepat dari yang seharusnya!

Shouji Takeshi:

Kami minta maaf.

Direktur Hashidate:

Apa kamu tidak apa-apa? Bisa berjalan sampai mobil?

Ayumi:

Sepertinya anaknya akan segera lahir...

Direktur Hashidate:

Tahan...jangan mengejan dulu.

Ayumi:

Ibu...aku sudah tidak tahan.

Direktur Hashidate:

Cepat panggil ambulans!

(Haken no Hinkaku, Episode 6)

$\begin{array}{llr}\text { Pada } & \text { data 5, Mori } & \text { Miyuki tidak } \\ \text { sengaja } & \text { meninggalkan } & \text { dokumen }\end{array}$ perusahaandi dalam taksi ketika pergi bekerja. Dokumen tersebut merupakan bahan presentasi besok pagi. Kesalahan yang dibuat oleh Mori tergolong ke dalam kesalahan yang berat karena seharusnya dokumen perusahaan tidak boleh dibawa pulang. Mori Miyuki meminta maaf kepada rekan-rekannya di Divisi Marketing. Sebagai bentuk tanggungjawab, Mori bergegas pergi untuk mencari dokumen tersebut. Ini dapat dilihat pada pernyataan Isoide sagashitekimasu 'saya akan segera mencarinya'.

Pada data 6, Shouji Takeshi dan Oomae Haruko datang langsung ke toko cokelat Silsimario untuk meminta maaf atas insiden yang terjadi. Akibat perdebatan di antara keduanya, cokelatcokelat yang diproduksi oleh Silsimario tidak laku terjual. Ini menyebabkan Direktur Hashidate (soto) tidak mau bekerjasama lagi dengan perusahaan $\mathrm{S} \& \mathrm{~F}$ (uchi) untuk project selanjutnya. Shouji Takeshi dan Oomae Haruko menunjukkan kesungguhan dengan meminta maaf sambil berlutut. Shouji berjanji bahwa cokelatcokelat yang tidak terjual tersebut tidak akan disia-siakan. Terlihat bahwa ekspresi formal moushiwake arimasen dan moushiwake gozaimasen dapat digunakan dalam situasi yang sama. Direktur Hashidate juga mengatakan kalau bekerja hingga larut membuat anaknya, Ayumi melahirkan lebih awal. Melihat hal tersebut, Oomae Haruko yang memiliki lisensi sebagai bidan bergegas menolong Ayumi.

\section{Menawarkan penggantian barang}

Strategi selanjutnya yang ditemukan adalah menawarkan penggantian barang. Dalam hal ini, pihak yang bersalah secara sengaja atau tidak telah merusak barang milik orang lain. Oleh karena itu, meminta maaf diiringi dengan menawarkan penggantian barang diharapkan dapat menebus ketidaknyamanan yang dirasakan oleh orang lain. Dalam sumber data hanya ditemukan 1 (satu) data yang memuat situasi terkait hal ini. 
Izumi, Volume 8 No 2, 2019

e-ISSN: 2502-3535 p-ISSN: 2338-249X

Tersedia online di http://ejournal.undip.ac.id/index.php/izumi

\section{Data 7}

美雪は、調子の悪いコーヒーサーバーを 吒いてみたところ、壊れてしまった。 そこへ匡子がやって来た。

黒岩匡子： あんたはこの間から大事な データは無くすし、ほんっ と疫病神ね。

森美雪： すみません。

黒岩匡子： どうするつもり！？

森美雪：弁償します！

黒岩匡子：これ高いのよ。15 万はした かな。

森美雪： 15 万！?

黒岩匡子： あなた今、自分で弁償しま すって言ったわよね。

森美雪： あ・あの・・分割でも いいでしょうか。

\section{Terjemahan}

Miyuki sedang memukul mesin pembuat kopi karena tidak berfungsi. Akibatnya, mesin tersebut rusak.

Masako datang dan melihat hal tersebut.

Kuroiwa Masako:

Baru-baru ini kamu menghilangkan data yang penting, sekarang berulah lagi.

Kamu ini benar-benar pembuat masalah ya.

Mori Miyuki:

Maaf.

Kuroiwa Masako:

Apa yang akan kamu lakukan?

Mori Miyuki:

Saya akan menggantinya!

Kuroiwa Masako:

Ini mahal lho...sekitar 150.000 yen

Mori Miyuki:

150.000 yen!?

Kuroiwa Masako:

Barusan kamu bilang akan menggantinya bukan?

Mori Miyuki:

Eh...kalau kredit bisa tidak ya?

(Haken no Hinkaku, Episode 2)

Pada data 7, Mori Miyuki dituduh oleh Kuroiwa Masako karena telah merusak mesin pembuat kopi. Mori yang merasa bersalah langsung meminta maaf dan menyatakan akan mengganti mesin yang rusak tersebut. Meskipun setelahnya Mori ragu karena harga mesin pembuat kopi cukup mahal. Pada akhir episode diketahui bahwa sebenarnya Kepala Bagian (Buchou) yang merusakkan mesin pembuat kopi tersebut.

5. Berjanji tidak akan mengulangi kesalahan yang sama

Salah satu strategi meminta maaf adalah dengan berjanji untuk tidak mengulangi kesalahan yang sama. Kondo \& Taniguchi (2008) juga mengemukakan bahwa orang Jepang menyukai permintaan maaf yang disertai dengan hansei (introspeksi diri). Dalam sumber data ditemukan 1 (satu) data yang memuat situasi di mana pihak yang bersalah mengungkapkan permintaan maaf dengan berjanji akan berhati-hati agar hal seperti ini tidak terulang kembali di masa yang akan datang. Kesalahan yang dilakukan tergolong berat dan melibatkan pihak di luar perusahaan (soto no mono).

\section{Data 8}

香が緑川からの電話を春子に回す。

東海林武：何で俺じゃないんだよ。

大前春子：お電話かわりました。

大前です。・・・はい。

緑川店長、それは、大変申

し訳ございませんでした。

こちらの担当者が不慣れな

もので。

緑川店長、これからはその

ようなことがないよう、

きちんと、申し伝えますの

で、はい。はい。・・・さ

あ、それは。

大丈夫です。売り場面積の

ことに関しては、私が把握

しておりますので。

$$
\text { ・・・かかました。 }
$$

緑川店長、本当に申し訳ご ざいませんでした。失礼い

たします。

東海林： 切るな、おい！ちょっと

あんた！

\section{Terjemahan}


Kaori memberitahu Haruko bahwa ada telepon dari Manajer Midorikawa.

Shouji Takeshi:

Kenapa bukan saya? (Shouji merasa bahwa seharusnya Manajer Midorikawa menghubungi dirinya yang seorang pegawai tetap).

Oomae Haruko:

Ini Oomae...Iya. Manajer Midorikawa mengenai hal tersebut saya sungguhsungguh minta maaf. Orang yang bertanggungjawab dalam hal ini masih tergolong baru.

Manajer Midorikawa, selanjutnya masalah seperti ini tidak akan terulang kembali. Saya akan menyampaikan kepadanya. Ya...ya.. mengenai hal itu saya juga tidak yakin.

Tidak apa-apa. Saya tahu luas area penjualan.

....Ya, saya mengerti.

Manajer Midorikawa, sekali lagi saya

benar-benar minta maaf. Selamat siang.

(Haken no Hinkaku, Episode 2)

Pada data 8, Oomae Haruko dihubungi oleh manajer dari salah satu departement store terkait kesalahan penghitungan area penjualan. Sebenarnya yang membuat kesalahan adalah Shouji Takeshi, manajer Divisi Penjualan tempat Oomae bekerja. Akan tetapi, Oomae meminta maaf atas kesalahan yang dibuat oleh Shouji karena tergabung dalam uchi yang sama. Situasi permintaan maaf ini bersifat formal, terlihat pada ekspresi yang digunakan, yaitu taihen moushiwake gozaimasendeshita.Selain itu, Oomae juga menyatakan bahwa kesalahan yang sama tidak akan terulang kembali. Kesungguhan juga ditunjukkan dengan meminta maaf lagi sebelum menutup telepon, terlihat pada kalimat hontouni moushiwake gozaimasendeshita. Pada data ini, juga diketahui bahwa orang Jepang meminta maaf dengan sedikit membungkukkan badan, meskipun melalui telepon.

\section{Aspek-aspek yang berperan dalam Pemilihan Ungkapan dan Strategi Permintaan Maaf}

Berdasarkan temuan dan analisis yang telah dipaparkan sebelumnya, diketahui bahwa pemilihan ungkapan permintaan maaf berikut strateginya di tempat kerja bergantung pada beberapa aspek, yaitu situasi, bobot kesalahan yang diperbuat, dan status lawan bicara. Situasi di tempat kerja terdiri atas situasi yang bersifat formal dan yang bersifat informal. Situasi formal misalnya pada saat rapat, diskusi, berhadapan dengan buchou dan membicarakan masalah kerjasama dengan perusahaan lain. Selanjutnya, situasi informal misalnya pada saat sebelum jam kerja dimulai, jam istirahat, dan setelah jam kerja berakhir.

Bobot kesalahan yang diperbuat juga ikut berperan. Kesalahan ringan seperti lupa memberi izin untuk pergi makan siang, menolak ajakan makan siang bersama, tidak serius ketika diajari oleh rekan kerja, dan tidak dapat membantu orang lain. Pada umumnya, ekspresi sumimasen atau gommennasai digunakan dalam situasi-situasi tersebut. Strategi permintaan maaf yang digunakan, yaitu IFID (meminta maaf secara langsung) dan memberikan alasan. Selanjutnya, kesalahan yang tergolong berat seperti tidak dapat menjual produk yang diproduksi perusahaan mitra dalam jumlah yang ditentukan dan melakukan kesalahan penghitungan area penjualan. Dalam situasi-situasi bisnis semacam ini ekspresi moushiwake arimasen atau moushiwake gozaimasen lebih sesuai untuk digunakan. Strategi yang dipilih juga lebih kompleks, yaitu berupa penjelasan dan menunjukkan sikap bertanggungjawab.

Status lawan bicara juga diperhatikan pada saat memilih ekspresi permintaan maaf dan strategi dalam meminta maaf. Misalnya, terlihat dalam situasi di mana haken meminta maaf kepada pegawai tetap yang berasal dari divisi lain. Dalam hal ini, ekspresi 
Izumi, Volume 8 No 2, 2019

e-ISSN: 2502-3535 p-ISSN: 2338-249X

Tersedia online di http://ejournal.undip.ac.id/index.php/izumi

sumimasen atau suimasen digunakan.

Akan tetapi, pada saat meminta maaf dengan pegawai tetap yang berasal dari divisinya, maka ekspresi gomennasai juga dapat digunakan selain sumimasen. Penggunaan ekspresi gomennasai menunjukkan hubungan yang dekat dengan rekan-rekan dan manajer yang tergabung dalam satu divisi. Akan tetapi, ekspresi ini diungkapkan jika kesalahan yang dibuat termasuk dalam kategori ringan. Jika kesalahan yang diperbuat tergolong berat, maka ekspresi moushiwake arimasen lebih sesuai untuk digunakan, meskipun permintaan maaf ditujukan kepada rekanrekan dari divisi yang sama.Selain itu, pada beberapa data juga terlihat bahwa pegawai tetap mengomentari kesalahan haken dengan bahasa Jepang informal, sedangkan haken merespon komentar tersebut minimal dengan menggunakan teineigo (bentuk sopan).

Contoh lain yang berkaitan dengan status lawan bicara terlihat ketika baik pegawai tetap maupun haken yang bekerja di perusahaan yang sama (uchi) meminta maaf kepada orang yang berasal dari perusahaan lain (soto). Dalam hal ini, baik pegawai tetap maupun haken menggunakan ekspresi moushiwake arimasen atau moushiwake gozaimasen. Sementara itu, perwakilan dari perusahaan lain mengomentari kesalahan yang diperbuat dengan bahasa Jepang informal. Dalam sumber data juga ditemukan situasi di mana pegawai tetap melimpahkan kesalahan kepada haken di depan pimpinan perusahaan lain. Padahal pegawai tetap yang memberikan instruksi kepada haken. Hal ini berkaitan dengan konsep omote (publik) dan ura (privat), di mana pegawai tetap berusaha untuk menyelamatkan wajah di depan pimpinan perusahaan lain.

Hal lain yang penulis amati dari sumber data adalah orang Jepang tidak hanya meminta maaf untuk dirinya sendiri, tetapi juga meminta maaf mewakili orang lain atau atas nama perusahaan (ditemukan sebanyak 18 data). Misalnya, terlihat pada data di mana Manajer Divisi meminta maaf atas pekerjaan yang dilakukan oleh rekannya yang dianggap tidak beres, Manajer Divisi mewakili Buchou (kepala bagian) meminta maaf kepada salah seorang pegawai karena perusahaan telah memutuskan untuk tidak lagi memperpanjang kontraknya, haken meminta maaf kepada perwakilan dari perusahaan lain atas kesalahan yang dibuat oleh pegawai tetap tempatnya bekerja, dan sebagainya. Melalui situasi-situasi ini dapat dilihat hubungan antar individu di tempat kerja. Individu dipandang sebagai bagian dari kelompok (baik kelompok kecil maupun besar), sehingga kesalahan yang dibuat oleh individu juga merupakan kesalahan kelompok.

\section{SIMPULAN}

Melalui drama Haken no Hinkaku diperoleh gambaran budaya permintaan maaf di tempat kerja di Jepang sebagai berikut:

1) Ungkapan permintaan maaf yang digunakan di tempat kerja bervariasi, dimulai dari yang informal hingga yang formal (ditemukan 23 jenis ungkapan permintaan maaf). Ini berkaitan dengan hubungan antar individu yang terlibat dalam situasi permintaan maaf. Selain itu, ungkapan permintaan maaf yang sama dapat diulang beberapa kali pada situasi yang sama untuk menunjukkan kesungguhan. Dalam menunjukkan kesungguhan digunakan intensifiers (hontou ni, makoto ni) diikuti dengan gerakan ojigi (membungkukkan badan) atau dogeza (berlutut).

2) Pada kesalahan yang tergolong berat dan berkaitan dengan kelancaran aktivitas di perusahaan, strategi permintaan maaf dengan menunjukkan sikap bertanggung jawab lebih disukai. Terkadang pihak yang dirugikan secara terang-terangan terlihat meminta pertanggungjawaban pihak yang 
bersalah. Selanjutnya, pada kesalahan yang tergolong ringan, strategi yang digunakan adalah meminta maaf secara langsung dan memberikan alasan atau penjelasan.

3) Aspek-aspek yang berperan dalam pemilihan ungkapan dan strategi permintaan maaf, yaitu situasi, bobot kesalahan yang diperbuat (ringan atau berat), dan status lawan bicara. Selain itu, juga terlihat aplikasi konsepkonsep yang berlaku dalam masyarakat Jepang, sepertiuchi (in-group) dan soto (out-group). Individu merupakan anggota dari suatu kelompok, maka kesalahan yang diperbuat oleh individu juga merupakan kesalahan kelompok. Oleh karena itu, individu diharapkan menjaga nama baik perusahaan terlebih dengan perusahaan mitra.

\section{DAFTAR REFERENSI}

Abedi, E. (2016). A Cross-Cultural Comparative Study of Apology Strategies Employed by Iranian EFL Learners and English Native Speakers. Advances in Language and Literary Studies, 7(5), 35-44. https://doi.org/10.7575/aiac.alls.v.7n. 5 p. 35

Aijmer, K. (2014). Conversational Routines in English: Convention and Creativity. Oxon: Routledge Taylor and Francis Group.

Bell, A. (2013). The Guidebook to Sociolinguistics (1 edition). West Sussex: Wiley-Blackwell.

Bella, S. (2014). A contrastive study of apologies performed by Greek native speakers and english learners of Greek as a foreign language. Pragmatics, 24(4), 679-713. https://doi.org/10.1075/prag.24.4.01b el

Chigako. (2018).「申し訳ありません」
「申し訳ございません」の意味と

使い方 - 2つの違いは? Retrieved

April 21, 2019, from

https://news.mynavi.jp/article/201801 31-577936/

Cohen, A. D., \& Olshtain, E. (1981).

Developing a Measure of

Sociocultural Competence: The Case of Apology. Language Learning: A Journal of Research in Language Studies, 31 (1), 113-134.

https://doi.org/http://dx.doi.org/10.11 11/j.1467-1770.1981.tb01375.x

Edwards, J. (2013). Sociolinguistics: A Very Short Introduction. New York: Oxford University Press.

Gudykunst, W. B. (2004). Bridging Differences: Effective Intergroup Communication. California: Sage Publications, Inc.

Holmes, J. (1990). Apologies in New Zealand English. Language in Society, 19(2), 155-199. Retrieved from https://www.jstor.org/stable/4168131

Ishihara, N., \& Maeda, M. (2010). Advanced Japanese: Communication in context. New York: Routledge Taylor and Francis Group.

Jung, S. (2004). Interlanguage pragmatics Apology speech acts. In C. L. Moder \& A. Martinovic-Zic (Eds.), Discourse Across Languages and Cultures (pp. 99-116). Philadelphia: John Benjamins Publishing Company. Kasper, G., \& Blum-Kulka, S. (1993). Interlanguage Pragmatics. (G. Kasper \& S. Blum-Kulka, Eds.), The Encyclopedia of Applied Linguistics. New York: Oxford University Press. https://doi.org/10.1002/97814051984 31.wbea 10562

Katyal, D. (2005). Learn to Speak and Write Japanese. New Delhi: Lotus Press.

Keshani, K., \& Heidari-Shahreza, M. A. (2017). A Comparative Study of Apology Strategy Use by Iranian and German EFL Learners : Gender 
Izumi, Volume 8 No 2, 2019

e-ISSN: 2502-3535 p-ISSN: 2338-249X

Tersedia online di http://ejournal.undip.ac.id/index.php/izumi

Differences in Focus. Journal of Applied Linguistics and Language Research, 4(1), 199-212. Retrieved from file://C:/Users/Eka Marthanty/Downloads/492-1479-1PB.pdf

Kondo, F., \& Taniguchi, H. (2008). A Comparative Study of Perceptions of Apology Strategies between Japanese and Americans. Gendai Shakaigaku, (9), 131-154. Retrieved from http://harp.lib.hiroshimau.ac.jp/hkg/detail/1037200807010916 55

Kothari, C. R. (2009). Research and Methodology: Methods and Techniques (Second Revised Edition) (Second Rev). New Delhi: New Age International Publishers.

Li, Z. (2018). Apology acts in Chinese and Japanese in home situations: Analysis of the apology discourse in television dramas. Journal of the Doctorate Studies in Social Sciences, 15, 117140. Retrieved from https://ir.kagoshimau.ac.jp/?action=pages_view_main\&ac tive_action=repository_view_main_it em_detail\&item_id $=14177 \& \overline{\text { item_no }}$ $=1$ \&page_id $=13 \&$ block_id $=21$

Nagumo, S., Sato, T., Shigeyama, Y., \& Yoshino, H. (2007). Haken no Hinkaku. Japan.

Saleem, T. (2014). The Use of Apology Strategies in English by Pakistani EFL University Students in Pakistan. Journal of Education and Practice, 5(34), 142-149.

Salehi, R. (2014). A Comparative Analysis of Apology Strategy: Iranian EFL
Learners and Native English Speakers.

Procedia - Social and Behavioral

Sciences, 98, 1658-1665.

https://doi.org/10.1016/j.sbspro.2014. 03.590

Sari, M. K. (2016). Apology Strategy in English By Native Speaker. Lingua Cultura, 10(1), 13. https://doi.org/10.21512/lc.v10i1.815

Shahrokhi, M., \& Jan, J. M. (2012). The Realization of Apology Strategies Among Persian Males. Procedia Social and Behavioral Sciences, 46, 692-700.

https://doi.org/10.1016/j.sbspro.2012. 05.183

Sugimoto, N. (1998). "Sorry We Apologize So Much ": Linguistic Factors Affecting Japanese and U.S. American Styles of Apology. Intercultural Communication Studies, 13(1), 71-78. Retrieved from https://web.uri.edu/iaics/files/06Naomi-Sugimoto.pdf

Tsuda, T. (2003). Strangers in the Ethnic Homeland: Japanese Brazilian Return Migration in Transnational Perspective. New York: Columbia University Press.

Ugla, R. L., \& Abidin, M. J. Z. (2016). A Study of Apology Strategies Used by Iraqi EFL University Students. International Journal of Evaluation and Research in Education, 5(1), 3238. Retrieved from http://search.ebscohost.com/login.asp $\mathrm{x}$ ?direct $=$ true $\& \mathrm{db}=$ eric $\& \mathrm{AN}=\mathrm{EJ} 1094$ $582 \&$ site $=$ ehost-live 